\title{
Assessment of maternal and child health care services performance in the context of COVID-19 pandemic in Addis Ababa, Ethiopia: evidence from routine service data
}

Senedu Bekele Gebreegziabher ${ }^{\text {* }}$, Solomon Sisay Marrye ${ }^{2}$, Tsegaye Hailu Kumssa ${ }^{1}$, Kassa Haile Merga Alemu Kibret Feleke ${ }^{3}$, Degu Jerene Dare ${ }^{4}$, Inger Kristensson Hallström ${ }^{5}$, Solomon Abebe Yimer ${ }^{6,7}$ and Mulatu Biru Shargie ${ }^{1,5}$

\begin{abstract}
Background: In many settings, health care service provision has been modified to managing COVID-19 cases, and this has been affecting the provision of maternal and child health services. The aim of this study was to assess trends in selected maternal and child health services performance in the context of COVID-19 pandemic.

Methods: A cross-sectional data review was conducted in Addis Ababa, Ethiopia from April to May 2021. Routine health management information system database was reviewed from Addis Ababa Health Bureau for the period from July 2019 to March 2021 across all quarters. Proportion and mean with standard deviation were computed. T-test was used to assess statistically significant differences in services mean performance.

Results: Postnatal care visit, new contraceptives accepters, safe abortion care and number of under- 5 years old children treated for pneumonia significantly decreased by 9.3\% (p-value 0.04), 20.3\% ( $p$-value 0.004), 23.7\% (p-value 0.01 ) and $77.2 \%$ ( $p$-value $<0.001$ ), respectively during the first 8 months of the COVID-19 pandemic compared to the previous 8 months' average performance. The trends in Antenatal care first visit, new contraceptive accepters, pentavalent-3 vaccination and under-five children treated for pneumonia began to decline in January to March 2020, a quarter when the COVID-19 pandemic began; with accelerated declines in April to June 2020 following national lockdown. The trends for the stated services began to increase during July-September 2020, the last quarter of national lockdown. Contraceptive accepters and pentavalent-1 vaccination continued to decline and showed no recovery until January-March 2021 when this study was completed.

Conclusions: Most of the maternal and child health services performance declined following the onset of COVID-19 pandemic and national lockdown, and most of the services began recovering during July-September 2020, the last quarter of national lockdown. However, new and repeat contraceptive accepters and pentavalent-1 recipients continue to decline and show no recovery during end of the study period. Implementing COVID-19 prevention measures and assuring the community about the safety of service delivery is imperative to ensure continuity of the maternal and child health services. Regular monitoring and evaluation of services performance is required to identify slowly recovering services and respond to potentially volatile changes during the COVID-19 pandemic.
\end{abstract}

*Correspondence: senedu.bekele@ahri.gov.et

${ }^{1}$ Armauer Hansen Research Institute (AHRI), Addis Ababa, Ethiopia

Full list of author information is available at the end of the article permits use, sharing, adaptation, distribution and reproduction in any medium or format, as long as you give appropriate credit to the original author(s) and the source, provide a link to the Creative Commons licence, and indicate if changes were made. The images or other third party material in this article are included in the article's Creative Commons licence, unless indicated otherwise in a credit line to the material. If material is not included in the article's Creative Commons licence and your intended use is not permitted by statutory regulation or exceeds the permitted use, you will need to obtain permission directly from the copyright holder. To view a copy of this licence, visit http://creativecommons.org/licenses/by/4.0/. The Creative Commons Public Domain Dedication waiver (http://creativeco mmons.org/publicdomain/zero/1.0/) applies to the data made available in this article, unless otherwise stated in a credit line to the data. 


\begin{abstract}
Plain English summary
The coronavirus disease 2019 (COVID-19) is the worst global health crisis of a century. In many settings, health care service provision has been modified to focus on managing COVID-19 cases, and this has been affecting the provision of health services including maternal and child health services. The aim of this study was to assess the trends in maternal and child health services performance in the era of COVID-19 pandemic in Addis Ababa, Ethiopia. The results of the studies showed post-delivery care, new family planning attendees, safe abortion care and number of under- 5 years old children treated for pneumonia decreased during the first 8 months of the COVID-19 pandemic compared to the previous 8 months' average performance. The trends in antenatal care (care during pregnancy), new family planning attendees, pentavalent-3 vaccination and under-five children treated for pneumonia began to decline between January-March 2020, a quarter when the COVID-19 pandemic began; with accelerated declines in April to June 2020 following national lockdown. The trends for the stated services began to increase during July-September 2020, the last quarter of national lockdown. Family planning attendees and pentavalent- 1 vaccination continued to decline and showed no recovery until January-March 2021 when this study was completed. Implementing COVID-19 prevention measures and assuring the community about the safety of service delivery is imperative to ensure continuity of the maternal and child health services. Regular monitoring and evaluation of services performance is required to identify slowly recovering services and respond to potentially volatile changes during the COVID-19 pandemic.
\end{abstract}

Keywords: COVID-19, Pandemic, Maternal, Child, Health services, Routine service data, Addis Ababa, Ethiopia

\section{Background}

The coronavirus disease 2019 (COVID-19) pandemic is the worst global health crisis of a century declared as a Public Health Emergency of International Concern by the World Health Organization (WHO) in March 2020 [1]. As of October 22, 2021, more than 243 million confirmed COVID-19 cases and 4,945,928 related deaths have been reported globally. The Africa region reported 8,528,131 cases and 216,956 related deaths in the same period [2].

The COVID-19 pandemic has challenged the resilience of the most effective health systems in the world [1]. In many settings, health care service provision has been modified to focus on managing COVID-19 cases, and this pandemic focused approach has been affecting the provision of routine health services including reproductive, maternal, neonatal and child health (RMNCH) services [3]. Essential health services including antenatal care (ANC), skilled birth attendance (SBA), postnatal care (PNC), and other sexual and reproductive health care services such as family planning (FP), post-abortion care, and, where legal, safe abortion services to the full extent of the law need to remain available [4]. The WHO recommends continuation of essential health services including maternal and child health $(\mathrm{MCH})$ services regardless of COVID-19 expansion taking into consideration the implication of interruption of those services in health care facilities [5]. However, many countries, particularly countries in Africa have faced substantial challenges to maintain the provision of high quality essential RMNCH services during COVID-19 pandemic [6]. The health care system in Africa faces several challenges such as: lack of funds, inequitable allocation of resources to the health sector, low healthcare workforce, high disease burden and inadequate health infrastructure. The already fragile health system in most countries in Africa is overburdened with additional mission to address COVID-19 pandemic [7].

Ethiopia reported the first confirmed COVID-19 case on 13th March 2020 [8]. Consequently, the government declared a national state of emergency on 8th April 2020 that would last until 10th September 2020 [9]. The country adopted a variety of response measures to mitigate the infection and halt the spread of the severe acute respiratory syndrome coronavirus 2 (SARS-CoV-2) [10]. The measures included travel restrictions, suspension of international flights, international border closure, mandatory quarantines, flexible working arrangements, suspending public gathering and sports, closure of schools and universities, requirements for social distancing and others $[10,11]$. Despite all the measures taken, however, the country reported the highest number of confirmed COVID-19 cases in the East Africa region. As of October 22, 2021, Ethiopia reported 361,027 confirmed cases and 6,316 COVID-19 related deaths [2]. Addis Ababa, the capital city of Ethiopia comprised more than $50 \%$ of total confirmed COVID-19 cases within the country [12].

The government of Ethiopia has identified $\mathrm{RMNCH}$ services as essential health services for improving maternal, neonatal and child health [13]. Substantial achievements in reducing maternal mortality ratio, under-5 and infant mortality rates have been documented during the last two decades in the country by implementing essential health services [14]. Maintaining access and utilization of essential health services in the era of the COVID-19 pandemic is crucial to prevent unfavorable outcomes and protect the gains made over the past years 
in reducing maternal, infant and child mortality rates [15]. In April 2020, the Ministry of Health-Ethiopia set a guide for maintaining essential health services during the COVID-19 pandemic [16].

Several studies from different countries around the world showed the negative impacts of COVID-19 pandemic on $\mathrm{MCH}$ services [17-21]. In Ethiopia, some studies from various regions showed reductions in $\mathrm{MCH}$ services during the early period of the COVID-19 pandemic $[6,11,22-24]$. However, trends in the $\mathrm{MCH}$ care services performance during and after national lockdown have not been adequately assessed, particularly in Addis Ababa, the capital city where most COVID-19 cases were detected. The aim of this study was to assess trends in selected $\mathrm{RMNCH}$ services performance indicators before, during and after national lockdown in the context of COVID-19 pandemic in Addis Ababa, Ethiopia.

\section{Methods}

\section{Study design and setting}

A cross-sectional data review was conducted in Addis Ababa City Administration Health Bureau (AACAHB), Ethiopia from April to May 2021 to assess trends in selected $\mathrm{MCH}$ health services performance in the context of COVID-19 pandemic. Addis Ababa is the capital city of Ethiopia, and is one of the most densely populated cities in the country, with an estimated population of more than five million in 2021 [25]. Ninety-five government health centres, 56 public hospitals and 66 private health care facilities are providing health services including $\mathrm{MCH}$ services in the city [26]. AACAHB is responsible for the health-care administration in the city.

\section{Data sources and management}

Routine health management information system (HMIS) RMNCH services database from AACAHB was reviewed to assess trends of selected $\mathrm{MCH}$ services performance indicators for the period starting from July 2019 to March 2021 across all quarters. The period from July 2019 to March 2021 covers the periods before, during and after lockdown time periods in Ethiopia. Two trained data collectors reviewed the data from April to May 2021. Data collectors were trained about the entire process of data collection including quality control measures such as: completeness, correctness, consistency, and synchronizing and archiving data with RedCap. The data reviewed included ANC, births attended by skilled health personnel at a health facility, early PNC (within seven days after delivery), contraceptives accepters, safe abortion care (abortion care provided at the time of induced abortion), post abortion care (abortion care provided during spontaneous abortion), early neonatal deaths (institutional neonatal deaths in the first 7 days of life), under-five children pneumonia treatment and immunization services. Regular supervision and follow-up were made throughout the data collection period. Completeness, correctness and consistency of the reviewed data were checked daily by supervisors. The overall activities and entire process of data collection were led by the principal investigator.

Precaution measures including maintaining wearing face mask, using hand sanitizers and physical distancing were implemented to prevent COVID-19 transmission during data collection.

\section{Data analysis}

The reviewed routine HMIS data were cleaned, checked for consistency and entered into the Redcap database, and the cleaned data were exported into Stata version15 statistical software package for statistical analysis. Descriptive statistics such as proportion and mean with standard deviation (SD) were computed. To assess changes in RMNCH services during the early period of COVID-19 pandemic, we compared the average services performance for the period March to October 2020 (the first 8 months of COVID-19 transmission in Ethiopia) with the July 2019 to February 2020 period (the preceding 8 months before COVID-19 transmission started). To assess trends in $\mathrm{MCH}$ services performance in the preCOVID period, during and after lockdowns, trends of selected RMNCH health services indicators were evaluated across quarters from July 2019 to March 2021. We used the first 3 months (July-September 2019) mean performance as a baseline to compute the relative percentage changes of the services performances for each quarter. T-test was computed to assess statistically significant differences in services mean performance. Test of normality was checked by histogram. A p-value of $<0.05$ was considered statistically significant.

\section{Ethical approval}

The Armauer Hansen Research Institute (AHRI) ethics review committee and the Addis Ababa City Administration ethics review committee approved this study. In addition, permission to review routine HMIS data was obtained from AACAHB authority.

\section{Results}

Maternal and child health services performance during the first 8 months of COVID-19 pandemic period Early PNC visit, new contraceptives accepters and safe abortion care significantly decreased by $9.3 \%$ ( $\mathrm{p}$-value 0.04 ), 20.3\% (p-value 0.004) and 23.7\% (p-value 0.01), respectively during the first 8 months (March-October 2020) of the COVID-19 pandemic compared to the previous 8 months' average performance. Similarly, there 
was a decrease in Pentavalent-1 vaccination (0.3\%), Pentavalent-3 vaccination (4.7\%) and fully vaccination (0.6\%) in the same period after COVID-19 pandemic. Measles first dose vaccination increased by $1.7 \%$ during MarchOctober 2020 compared to the period July 2019-February 2020 average performance. The average number of under-5 years old children treated for pneumonia was significantly reduced by $77.2 \%$ (p-value $<0.001$ ) in the period March-October 2020. However, there were increment in ANC four or more visits $(+1.2 \%)$ and post abortion care $(+17.8 \%)$ during the same period (Table 1$)$.

The average number of institutional neonatal deaths in the first 7 days of life in the periods covering July 2019 to February 2020 and March to October 2020 was 105 and 119 , respectively. Institutional neonatal deaths increased by $13.3 \%$ from July 2019 to February 2020 to March to October 2020 (p-value $=0.02)$.

\section{Trends in the maternal and child health services}

Services trend analysis across quarters for the period July 2019 to March 2021 showed that ANC first visit began to decrease in the period January to March 2020 (a quarter at the onset of COVID-19 in Ethiopia), with accelerated decline during April-June 2020 (national lockdown declared to control COVID-19). ANC four or more visits began declining during October-December 2019 (before onset of COVID-19 pandemic in Ethiopia), and began to recover in January to March 2020 then declined in the period April-June 2020 (Fig. 1a). Compared to the baseline performances, quarterly percentage changes in ANC visits across quarters for the period October 2020 to March 2021 showed that ANC first visit reduced by 9.5\% for the period April-June 2020 compared to the July-September 2019 average performance. ANC four or more visits reduced by $9.8 \%$ and $8.9 \%$, respectively during October-December 2019 and April-June 2020 compared to the July-September 2019 average performance (Fig. 1b). ANC first and four or more visits started to increase during the period July-September 2020 (the second quarter of national lock down) to a level higher than pre-pandemic baseline level (Fig. 1a).

Early PNC visit slightly declined in the periods October-December 2019 and January-March 2020, with accelerated decline during April-June 2020. For the period April-June 2020, early PNC visit decreased by $17.5 \%$ compared to the July-September 2019 average performance. PNC visit continuously increased across quarters in the periods July to September 2020, October to December 2020 and January to March 2021. The percentage change in early PNC visit across quarters of the study periods was statistically significant with p-values 0.04 and 0.05 in April-June 2020 and July-September 2020, respectively (Table 2 ).

Trend analysis of contraceptives accepters showed that the average number of new contraceptives accepters began to decline during January-March 2020, with accelerated decline in the period April-June 2020. Repeat contraceptives accepters began to reduce during

Table 1 Maternal and child health services during the first 8 months of COVID-19, Addis Ababa, Ethiopia

\begin{tabular}{|c|c|c|c|c|c|}
\hline Health services & Indicators & $\begin{array}{l}\text { July 2019- } \\
\text { February } 2020 \\
\text { Baseline mean }\end{array}$ & $\begin{array}{l}\text { March-October } \\
2020 \\
\text { Mean }\end{array}$ & $\begin{array}{l}\text { Percentage } \\
\text { change (\%) }\end{array}$ & p-value \\
\hline \multirow[t]{8}{*}{ Maternal health services } & ANC first visit & $13,780.75$ & 12,811 & -7.0 & 0.15 \\
\hline & ANC four or more visits & $10,469.75$ & $10,597.75$ & +1.2 & 0.79 \\
\hline & Health facility births & $11,745.13$ & $11,454.13$ & -2.5 & 0.50 \\
\hline & Early PNC visit & $11,588.13$ & $10,514.5$ & -9.3 & $0.04^{*}$ \\
\hline & New contraceptives accepters & $10,054.5$ & 8014.5 & -20.3 & $0.004^{*}$ \\
\hline & Repeat contraceptives accepters & $18,742.5$ & $16,967.38$ & -9.5 & 0.10 \\
\hline & Safe abortion care & 2739.5 & 2091.25 & -23.7 & $0.01^{*}$ \\
\hline & Post abortion care & 1010.5 & 1189.87 & +17.8 & 0.21 \\
\hline \multirow[t]{5}{*}{ Child health services } & Pentavalent-1 vaccination ${ }^{a}$ & $11,037.88$ & $11,008.88$ & -0.3 & 0.94 \\
\hline & Pentavalent-3 vaccination ${ }^{b}$ & $11,198.5$ & $10,667.25$ & -4.7 & 0.27 \\
\hline & First dose measles vaccination & 9990.37 & $10,160.5$ & 1.7 & 0.86 \\
\hline & Fully vaccination & 9626.37 & 9572.87 & -0.6 & 0.95 \\
\hline & Under five children pneumonia treatment & 4861.87 & 1108.37 & -77.2 & $<0.001^{*}$ \\
\hline
\end{tabular}

This table shows the maternal and child health services performance during the first 8 months (March-October 2020) of the COVID-19 pandemic period compared to the baseline (July 2019-February 2020) average performance, Addis Ababa, Ethiopia

a First dose pentavalent vaccination

${ }^{\mathrm{b}}$ Third dose pentavalent vaccination

*p-value $<0.05$ 


\begin{tabular}{|l|l|l|l|l|l|l|l|l|l|l|l|}
\hline & \\
\hline
\end{tabular}

Table 2 Postnatal care across quarters for the period July 2019-March 2021, Addis Ababa, Ethiopia

\begin{tabular}{lllll}
\hline Months/quarters & $\begin{array}{l}\text { Early PNC visit } \\
\text { Frequency (N) }\end{array}$ & $\begin{array}{l}\text { Early PNC visit } \\
\text { (mean } \pm \text { SD) }\end{array}$ & Percentage change & p-value \\
\hline July-September 2019 & 35,233 & $11,744.33$ & Baseline \\
October-December 2019 & 34,323 & $11,441 \pm 1936.52$ & $-2.6 \%$ & - \\
January-March 2020 & 34,098 & $11,366 \pm 1292.48$ & $-3.2 \%$ & 0.81 \\
April-June 2020 & 29,042 & $9680.66 \pm 717.86$ & $-17.5 \%$ & 0.67 \\
July-September 2020 & 32,344 & $10,781.33 \pm 393.84$ & $-8.2 \%$ & $0.04^{*}$ \\
October-December 2020 & 33,031 & $11,010.33 \pm 1899.69$ & $-6.3 \%$ & $0.05^{*}$ \\
January-March 2021 & 35,135 & $11,712 \pm 1341.91$ & $-0.3 \%$ & 0.57 \\
\hline
\end{tabular}

$S D$ standard deviation

${ }^{*}$ p-values $<0.05$

October-December 2019, and continuously decreased in the periods January to March 2020 and April to June 2020 (Fig. 2a). The percentage changes showed that new and repeat contraceptives accepters were reduced by $13.1 \%$, $28 \%, 16.1 \%$ and $24.3 \%$, respectively in the periods January to March 2020 and April to June 2020 compared to the July to September 2019 period average performance (Fig. 2b). During the periods July to September 2020 and October to December 2020, new contraceptives accepters continuously increased, but not to the pre-pandemic levels. The number of repeat contraceptives accepters began to increase during July-September 2020, with progressive increment between October-December 2020 to a level higher than the pre-pandemic level (Fig. 2a). In the last quarter of the study period (January-March 2021), new and repeat contraceptives accepters decreased by $26 \%$ and $8.3 \%$, respectively compared to the July to
September 2019 period (Fig. 2b). The percentage change in new and repeat contraceptives accepters for the period April-June 2020 was statistically significant with p-values 0.04 and 0.03 , respectively.

Across quarters for the periods July 2019 to March 2021, Pentavalent-1 vaccination recipients decreased during October to December 2019, January to March 2020, October to December 2020 and January to March 2021. Pentavalent-3 vaccination recipients began to decrease during January to March 2020, with accelerated reduction in the period April to June 2020 (Fig. 3a). Percentage changes showed that Pentavalent- 1 vaccination recipients declined by $5.1 \%, 11.0 \%, 7.5 \%$ and $8.3 \%$, respectively in the periods October to December 2019, January to March 2020, October to December 2020 and January to March 2021 compared to the July to September 2019 period. Pentavalent-3 vaccination recipients 


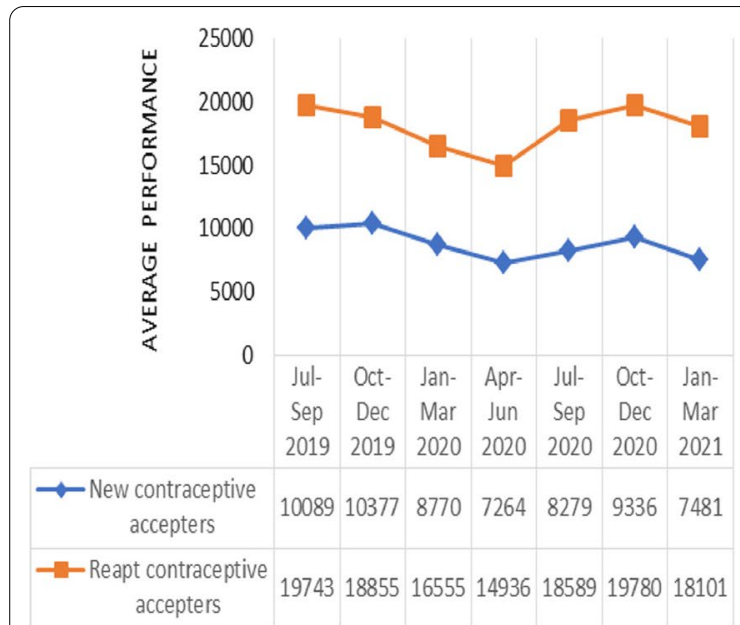

a

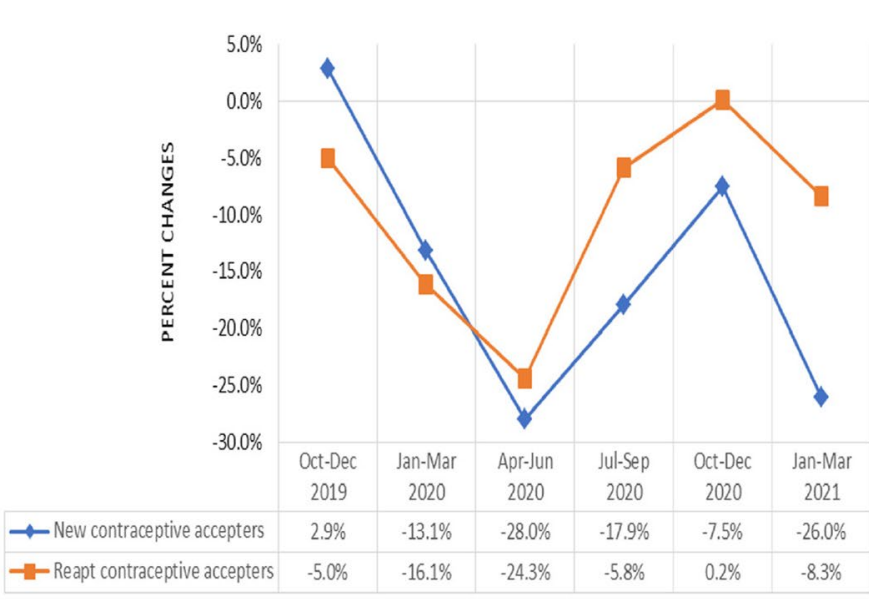

b

Fig. 2 Trends in mean number and percentage changes in contraceptive accepters across quarters. a shows trends in mean number of contraceptive accepters across quarters from July 2019 to March 2021 and $\mathbf{b}$ shows percentage changes in contraceptive accepters across quarters from October 2019 to March 2021 compared to baseline (July-September 2019) average performance, Addis Ababa, Ethiopia

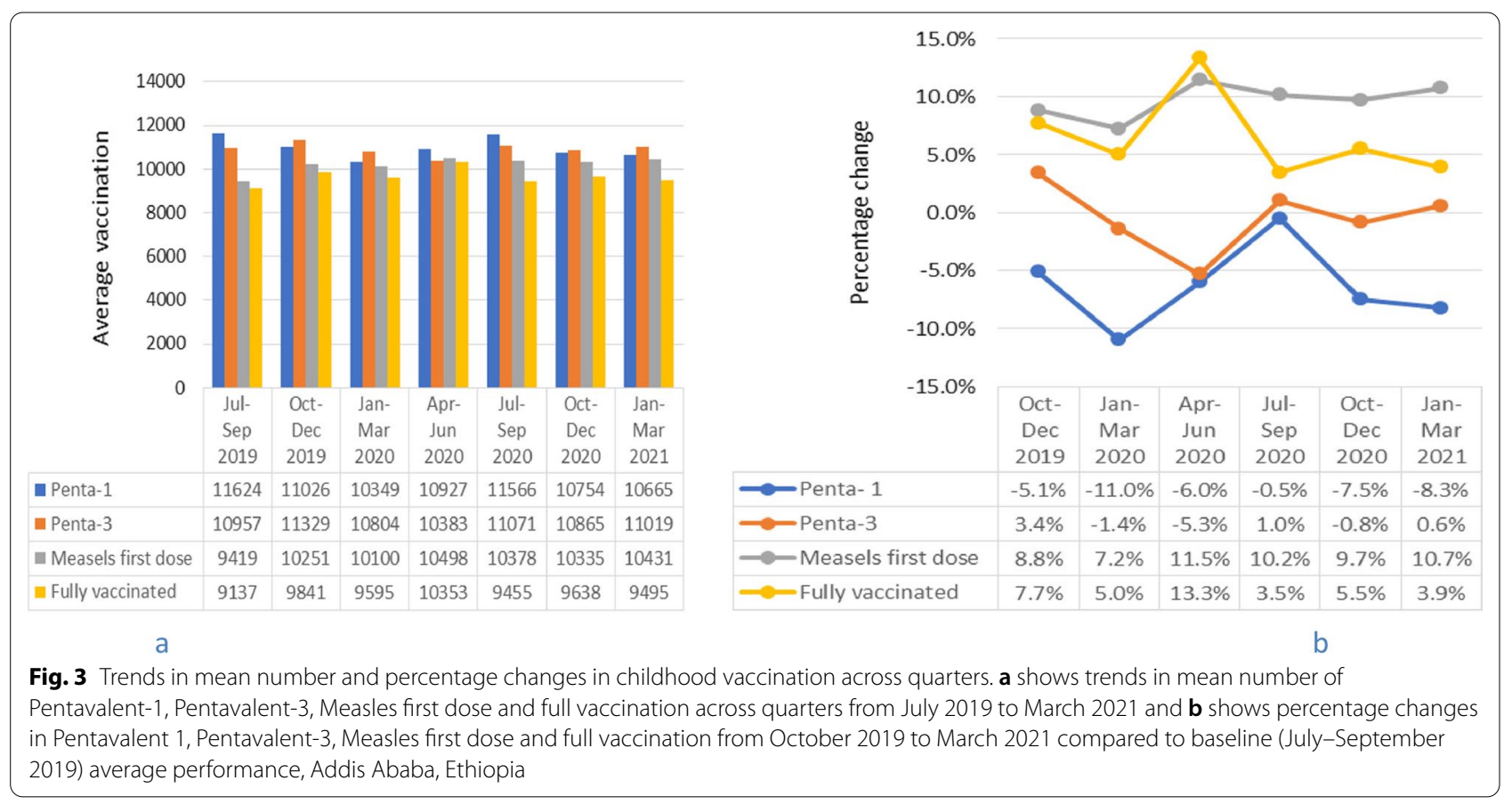

decreased by $5.4 \%$ during April-June 2020 compared to the July-September 2019 period (Fig. 3b). The percentage change in Pentavalent-1 vaccination performance was statistically significant for the period October-December 2020 with $p$-value $=0.05$. Pentavalent- 1 vaccination performance recovered during April-June 2020 and JulySeptember 2020 periods, but not to the pre-pandemic level. In the period July to September 2020, Pentavalent-3 vaccination performance recovered to a level higher than the pre-pandemic baseline then slightly declined during October-December 2020, but again increased in the period January-March 2021. Measles first dose and fully vaccinations remained higher than the pre-pandemic baseline levels across quarters in the periods October 2019 to March 2021. The highest increment was observed in April-June 2020 (Fig. 3a). Measles first dose and fully 
vaccinations increased by about $11.5 \%$ and $13.3 \%$, respectively in the April-June 2020 (lock down) period compared to July-September 2019 (Fig. 3b).

The average number of children under 5 years old treated for pneumonia began to decline in the period January to March 2020 with accelerated decline during April to June 2020 and July to September 2020 study periods (Fig. 4a). In the periods April to June 2020 and July to September 2020, the average number of children under-5 years old treated for pneumonia was reduced by $86.2 \%$ and $86.3 \%$, respectively compared to the July to September 2019 period (Fig. 4b). The average number of children under- 5 years old treated for pneumonia recovered during the period October-December 2020 and JanuaryMarch 2021, but not to the pre-pandemic level (Fig. 4a). Compared to the baseline, the percentage change in average number of children under- 5 years old treated for pneumonia was statistically significant with p-values 0.04, 0.01, 0.02 and 0.05 in the periods April-June 2020, July-September 2020, October-December 2020 and January-March 2021, respectively.

\section{Discussions}

ANC first visit, health facility delivery, early PNC, new contraceptive accepters, repeat contraceptive accepters, safe abortion care, pentavalent- 3 recipients and number of under- 5 years old children treated for pneumonia decreased by $7 \%, 2.5 \%, 9.3 \%, 20.3 \%, 9.5 \%, 23.7 \%, 4.7 \%$ and $77.2 \%$, respectively in the first 8 months of the COVID19 pandemic compared to the pre-pandemic average performance. This might be related to inadequate supply of personal protective equipment, redirecting human workforce and services towards responding to COVID19 pandemic. In addition, fear of acquiring COVID-19 by clients/patients if attended health facilities and financial barriers to seek health services might negatively affect services utilization [26, 27].

Early PNC visit significantly declined by $9.3 \%$ in the period March to October 2020 compared to the July 2019 to February 2020 period. Similarly, a study conducted in South West Ethiopia showed that PNC decreased by $29.1 \%$ in the period March-June 2020 [26]. PNC is a critical time for the well-being of mothers and newborns as most maternal deaths occur during the postpartum period, particularly within the first two days following delivery. Health professionals can use the opportunity to provide care while the mother is already in a health facility; however, this is the most neglected period for the provision of quality services $[24,28]$. Likewise, safe abortion care significantly decreased by $23.7 \%$ in the same period. This finding is in line with a case study conducted at a tertiary facility in Addis Ababa whereby a decline of $14.5 \%$ was reported in safe abortion service during the period March-May 2020 [24]. On the other hand, in this study, post abortion care increased by $17.8 \%$ in the first 8 months during the COVID-19 pandemic. This is consistent with the results of a study conducted in another region of Ethiopia [27]. In Kenya $45 \%$ of pregnancies ended up with severe abortion complications during the COVID-19 pandemic [29]. The increased post abortion care in our study might be explained by women, who

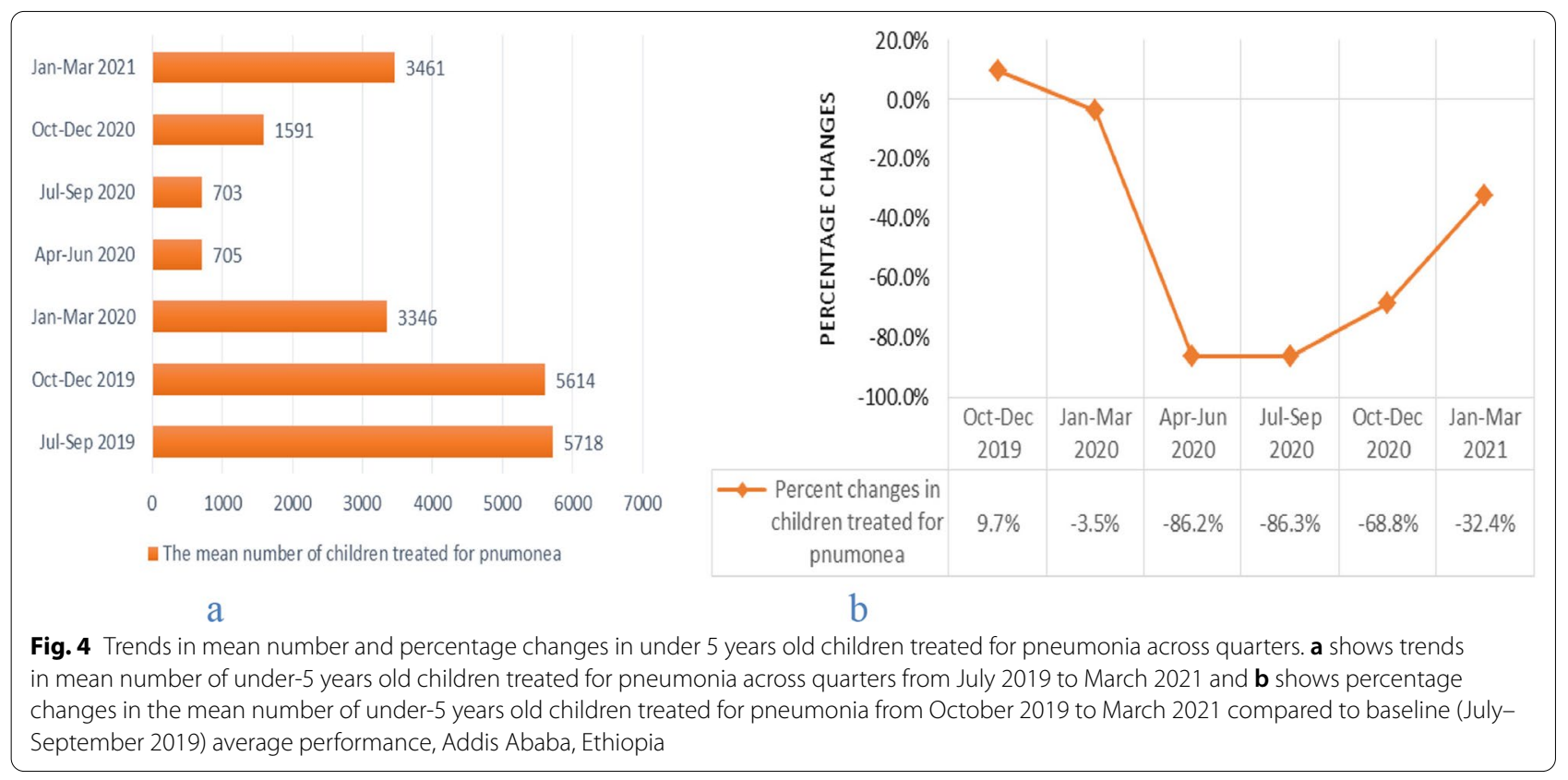


stayed at home during lockdown, were more prone to sexual abuse including rape even by their partners [30].

Institutional early neonatal death significantly increased by $13.3 \%$ in the period March-October 2020 compared to July 2019-February 2020. This is consistent with finding of a study done in Nepal [19]. In the Ethiopian context, institutional early neonatal death mainly defines the quality of obstetric care in a health facility [31]. The increase in institutional early neonatal death in this study may be related to compromised Intensive Care Units (ICUs) services; both space and equipment were redirected to COVID-19 care. Also, experienced ICUs staffs were more likely to be moved to COVID-19 treatment centers. Our study result underscores the importance of strengthening quality of health care services.

The percentage of Pentavalent- 1 and Pentavalent- 3 recipients and full vaccinated children decreased in the period March-October 2020 compared to the July 2019February 2020 average performance. This is consistent with findings of study conducted in India [1]. The desire to decrease COVID-19 spread in health care facilities and the repurposing of health workers may have led to hesitation to continue routine immunization services in health facilities during the early period of the COVID-19 pandemic [20].

The trends in most of the services began to decline during January-March 2020, a quarter when COVID19 began in Ethiopia. This was a time when the daily COVID-19 reported cases in Ethiopia, particularly in Addis Ababa were high [32]. In Ethiopia, as part of early response, there was intense media coverage about the COVID-19 outbreak, particularly in March 2020 after the country reported the first confirmed case. This might make the public fear of disease transmission and may have forced them to stop using health care services [27].

Some services including ANC four or more visits, early PNC visit, repeat contraceptive accepters and pentavalent-1 vaccination began to decline during October-December 2019 a quarter preceding the onset of COVID-19 pandemic in Ethiopia. The reductions in these services may be related to other reasons.

In this study, accelerated decline was observed in ANC first visit, ANC four or more visits, early PNC visit, new contraceptive accepters, repeat contraceptive accepters, pentavalent- 3 recipients and the number of under-five children treated for pneumonia during April-June 2020 following national lockdown. The lockdown period in Ethiopia has been accompanied by measures including travel restrictions, flexible working arrangements, suspending public gathering and requirements for social distancing $[10,11]$. This may have negative consequences on access to health services. Findings of studies in other regions of Ethiopia [11, 27] and other countries [17] also revealed decline trends of $\mathrm{MCH}$ services during lockdown.

ANC first visit declined during the first 8 months of the pandemic compared to the previous 8 months average performance. On the other hand, a relative increase was observed in ANC four or more visits during the same period. The possible explanation might be that the three previous ANC visits occurred before March 2020 when Ethiopia reported its first confirmed COVID-19 case. Trend assessment showed that both ANC first and four or more visits recovered and reached above the prepandemic baseline level average performance during the July-September 2020 (the last quarter of national lockdown) period. This may be related to an increased awareness of pregnant women about the disease transmission and its prevention method, which might have helped them to decrease their fear on COVID-19 and to visit health care facilities [11]. Also, a continuous services performance improvement across quarters in early PNC visit was observed since July-September 2020. In particular, in the last quarter of the study period (January-March 2021), recovery almost approached to pre-pandemic baseline level, and this was found to be an encouraging trend. These increasing trends in service provision may be due to efforts of the government to disseminate information on basic infection prevention control methods and guidance on safe care-seeking behavior [33]. Similarly, a study conducted in some districts of four regions in Ethiopia showed that most maternal health care services had already recovered by the end of July 2020 [11].

New contraceptive accepters significantly decreased by $20.3 \%$ and repeat contraceptive accepters decreased by $9.5 \%$ in the first 8 months of the COVID-19 pandemic. A study conducted in India showed a reduction in FP services in March 2020 compared to December 2019 [34]. Services performance recovery in contraceptive accepters was observed in the periods July-September 2020 and October-December 2020; however, new and repeat contraceptive accepters again began to decline and no recovery was observed in the period January-March 2021. Evidence indicates that a decrease in access to FP services results in increased poor outcomes related to unintended pregnancies and abortions [35]. The magnitude of unintended pregnancy during the COVID-19 pandemic among women attending ANC was $47.2 \%$ in Northwest Ethiopia [32].

The trend in Measles first dose vaccination across quarters remained above the pre-pandemic baseline level, although a slight positive decrement trend was observed during the periods January-March 2020, July-September 2020 and October-December 2020. Accelerated increment was observed in the period April-June 2020 following lockdown. This may be explained by the nationwide 
home to home campaign that was conducted in June 2020 in Ethiopia. About 15 million children have been vaccinated against measles in Ethiopia in an effort by the Ministry of health to maintain essential services despite COVID-19 challenges [36]. The country undertook the campaign taking into account the local COVID-19 transmission and implementing COVID-19 prevention measures [20]. Similarly, the trend in fully vaccination across quarters remained above the pre-pandemic baseline level with accelerated increment during April-June 2020 following lockdown. Nonetheless, positive decrement trend was observed in the periods July-September 2020 and at the end of the study period (January-March 2021).

Although increasing trend was observed in pentavalent-1 vaccination in April-June 2020 and July-September 2020, it continuously declined in the periods October to December 2020 and January to March 2021. A review of routine immunization data from 15 African countries showed that the number of children vaccinated with DPT1, DPT3 and MCV1 declined in the early period of the COVID-19 pandemic [20]. During an epidemic, even a temporary interruption of routine immunization services may lead to secondary health crises such as outbreaks during or after the recovery phase [37]. The deaths prevented by sustaining routine childhood immunization in Africa outweigh the excess risk of COVID-19 deaths associated with vaccination clinic visits, especially for the vaccinated children [38].

There has been a dramatic reduction in the average number of children under- 5 years old treated for pneumonia in the first 8 months of the COVID-19 pandemic compared to the preceding 8 months. Also, we observed significant and accelerated decline trend in the periods April-June 2020 and July-September 2020 (during national lockdown). This may be due to the reduced under-five clinic services provision by health care facilities or reduced demand for health care services by clients/patients. However, in the periods OctoberDecember 2020 and January to March 2021 (after lockdown), slow reversal in a negative trend was observed, but does not appear to have recovered to the pre-pandemic baseline level. Pneumonia is the leading cause of under-five morbidity and mortality in Ethiopia, accounting $18.0 \%$ of all causes of mortality and killing over 40,000 children in under-five age group every year in the country [39]. Therefore, further study is warranted to investigate the reasons for the declining trend of under- 5 years old children treated for pneumonia.

This study attempted to understand the performance status of selected $\mathrm{RMNCH}$ services using routine data in the context of COVID-19 pandemic. However, other studies showed high rates of inaccuracies in health records in Ethiopia [40, 41], and as we used routine
HMIS data this study may share the inherent limitation of secondary data such as: inconsistency, incompleteness and inaccuracy. Nevertheless, extensive efforts have been made by the research team to ensure the data quality. The data collectors and supervisors cross checked the HMIS data at health facilities level whenever discrepancies occurred during the data review period.

\section{Conclusions}

Most of the MCH services performance declined following onset of COVID-19 and national lockdown period in Addis Ababa, Ethiopia. Most of the $\mathrm{MCH}$ services began recovering in the period July-September 2020, the last quarter of national lockdown. In the last quarter of the study period, ANC first and four visits, PNC visit and the percentage of Pentavalent- 3 recipients recovered to a level higher than the pre-pandemic baseline level. Measles first dose recipients and number of fully vaccinated remained above the pre-pandemic level across quarters. Although, new and repeat contraceptive accepters and pentavalent- 1 recipients began recovering in July-September 2020, these services performance continued to decline and showed no recovery by end of the study period. The mean number of under-five children treated for pneumonia significantly declined across quarters, although slight recovery was observed in the last two quarters of the study period. This implies longer-term negative effects of COVID-19 on reproductive, maternal and child health services. Therefore, the Addis Ababa Health Bureau authorities should ensure the continuity of these services by implementing the required COVID-19 prevention measures and assuring the community about the safety of service delivery. Regular monitoring and evaluation of services performance is required to identify slowly recovering services and respond to potentially volatile changes during the COVID-19 pandemic.

\section{Abbreviations \\ AACAHB: Addis Ababa City Administration Health Bureau; AHRI: Armauer Hansen Research Institute; ANC: Antenatal care; COVID-19: Coronavirus disease 2019; FP: Family planning; HMIS: Health management information system; MCH: Maternal and child health; RMNCH: Reproductive, maternal, neonatal and child health; PNC: Postnatal care; SARS-CoV-2: Severe acute respiratory syndrome coronavirus 2; SBA: Skilled birth attendance; WHO: World Health Organization.}

\section{Acknowledgements}

We would like to thank the Armauer Hansen Research Institute for funding this study. We also would like to thank the Addis Ababa City Administration Health Bureau for unlimited support. We are very much grateful to data collectors.

\section{Authors' contributions}

SBG, MBS, KHM, THK, AKF, SAY, DJD and IKH designed the study. SBG, SSM and AKF conducted the data collection. SBG, SSM and THK performed the data analysis. SBG, MBS, KHM, THK, AKF, SAY, DJD and IKH drafted the manuscript. 
SBG, MBS, KHM, THK, SAY, DJD and IKH edited the manuscript. All authors finally read and approved the final manuscript.

\section{Funding}

AHRI funded the study. The funder had no role in study design, data collection and analysis, decision to publish, or preparation of the manuscript.

\section{Availability of data and materials}

The datasets used and/or analyzed during the current study are available from the corresponding author on reasonable request.

\section{Declarations}

\section{Ethics approval and consent to participate}

The AHRI ethics review committee and the Addis Ababa City Administration ethics review committee approved this study. In addition, permission to review routine HMIS data was obtained from AACAHB authority.

\section{Consent for publication}

"Not applicable" in this section.

\section{Competing interests}

The authors declare that they have no competing interest.

\section{Author details}

${ }^{1}$ Armauer Hansen Research Institute (AHRI), Addis Ababa, Ethiopia. ${ }^{2} \mathrm{KNCV}$, Addis Ababa, Ethiopia. ${ }^{3}$ Yekatit-12 Hospital Medical Collage Public Health Department, Addis Ababa, Ethiopia. ${ }^{4}$ KNCV Tuberculosis Foundation, Hague, The Netherlands. ${ }^{5}$ Department of Health Sciences, Child and Family Health, Lund University, Stockholm, Sweden. ${ }^{6}$ Vaccine Research and Development Department, Coalition for Epidemic Preparedness Innovations (CEPI), Oslo, Norway. ${ }^{7}$ Faculty of Medicine, Unit for Genome Dynamics, University of Oslo, Oslo, Norway.

Received: 25 October 2021 Accepted: 29 January 2022

Published online: 14 February 2022

\section{References}

1. Singh AK, Jain PK, Singh NP, Kumar S, Bajpai PK, Singh S, Jha M. Impact of COVID-19 pandemic on maternal and child health services in Uttar Pradesh, India. J Family Med and Prim Care. 2021;10:509-13.

2. Worldometers. COVID-19 Corona virus Pandemic. Accessed 22 Oct 2021: https://www.worldometers.info/coronavirus/.

3. Ameh C, Banke-Thomas A, Balogun M, Makwe CC, Afolabi BB. Reproductive maternal and newborn health providers' assessment of facility preparedness and its determinants during the COVID-19 pandemic in Lagos. Nigeria Am J Trop Med Hyg. 2021;104:1495-506.

4. Ombere SO. Access to maternal health services during the COVID-19 pandemic: experiences of indigent mothers and health care providers in Kilifi County. Kenya Front Sociol. 2021;6:613042.

5. Word Health Organization. Maintaining essential health services: operational guidance for the COVID-19 context. Interim guidance 1 June 2020. Accessed 2 Sept 2021: https://apps.who.int/iris/bitstream/handle/10665/ 332240/WHO-2019-nCoV-essential_health_services-2020.2-eng.pdf.

6. Tadesse E. Antenatal care service utilization of pregnant women attending antenatal care in public hospitals during the COVID-19 pandemic period. Int J Womens Health. 2020;12:1181-8.

7. Ogunkola IO, Adebisi YA, Imo UF, Odey GO, Esu E, Lucero-Prisno DE. Impact of COVID-19 pandemic on antenatal healthcare services in SubSaharan Africa. Public Health Pract. 2021;2:100076.

8. World Health Organization. First case of COVID-19 confirmed in Ethiopia, 13 March 13, 2020. Accessed 24 Sept 2020: https://www.afro.who.int/ news/first-case-covid-19-confirmed-ethiopia.

9. The Federal Democratic Republic of Ethiopia. A Regulation Issued to Implement the State of Emergency Proclamation No. 3/2020 Enacted to Counter and Control the Spread of COVID-19 and Mitigate its Impact. Council of Ministers Regulation No. 466/2020. 20th April 2020. Addis Ababa, Ethiopia.
10. Deressa W, Worku A, Amogne W, Getachew S, Kifle A, Abebe W. Knowledge and perceptions of COVID-19 among government employees in Ethiopia: a cross-sectional study. J Health Dev. 2020;35:000-000.

11. Workicho A, Kershaw MJ, Berhanu L, Kebede M, Kennedy E. Essential health and nutrition service provision during the COVID-19 pandemic: lessons from select Ethiopian Woredas. Curr Dev Nutr. 2021. https://doi. org/10.1093/cdn/nzab024.

12. Ethiopian Public Health Institute. National Public Health Emergency Operation Center, Ethiopia. COVID-19 Pandemic Preparedness and Response in Ethiopia weekly bulletin. Bulletin No. 63, July 2021. Accessed 1 Oct 2021: https://ephi.gov.et/wp-content/uploads/2021/02/EPHI_ PHEOC_COVID-19_Weekly_Bulletin_63_English_07192021.pdf.

13. Federal Ministry of Health. Essential Health Services Package of Ethiopia. November 2019; Addis Ababa, Ethiopia. Accessed 10 Aug 2021: https:// www.humanitarianresponse.info/sites/www.humanitarianresponse.info/ files/documents/files/essential_health_services_package_of_ethiopia_ 2019.pdf.

14. Ministry of Health Ethiopia. Annual performance report EFY 2012 (2019/2020). Accessed 25 Sept 2021: https://www.moh.gov.et/ejcc/am/ Annual_Performance Report_2012(2019 2020).

15. Global financing facility: preserve essential health services during the COVID-19 pandemic Ethiopia. Accessed 22 Sept 2021: https://www.globa Ifinancingfacility.org/sites/gff_new/files/documents/Ethiopia-CovidBrief_GFF.pdf.

16. Federal Ministry of Health of Ethiopia (FMoH). National Comprehensive COVID-19 Management Handbook. Addis Ababa: FMoH 2020. Accessed 27 Sept 2021: https://www.moh.gov.et/ejcc/am/NATIONAL\%20COM PREHENSIVE\%20COVID19\%20MANAGEMENT\%20HANDBOOK.

17. Ahmed T, Rahman AE, Amole TG, Galadanci H, Matjila M, Soma-Pillay $P$, et al. The effect of COVID-19 on maternal newborn and child health $(\mathrm{MNCH})$ services in Bangladesh, Nigeria and South Africa: call for a contextualized pandemic response in LMICs. Int J Equity Health. 2021;20:77.

18. Townsend R, Chmielewska B, Barratt I, Kalafat E, Meulen J, Gurol-Urganci I, et al. Global changes in maternity care provision during the COVID19 pandemic: a systematic review and meta-analysis. E Clin Med. 2021:37:100947.

19. Ashish KC, Gurung R, Kinney MV, Sunny AK, Moinuddin M, Basnet O, et al. Effect of the COVID-19 pandemic response on intrapartum care, stillbirth, and neonatal mortality outcomes in Nepal: a prospective observational study. Lancet Glob Health. 2020. https://doi.org/10.1016/S2214-109X(20) 30345-4.

20. Masresha BG, Luce R Jr, Shibeshi ME, Ntsama B, N'Diaye A, Chakauya J, et al. The performance of routine immunization in selected African countries during the first six months of the COVID-19 pandemic. Pan Afr Med J. 2020;37(Suppl 1):12

21. Chandir S, Siddiqi DA, Mehmood M, Setayesh H, Siddique M, Mirza A, et al. Impact of COVID-19 pandemic response on uptake of routine immunizations in Sindh, Pakistan: an analysis of provincial electronic immunization registry data. Vaccine. 2020;38:7146-55.

22. Temesgen K, Wakgari N, Debelo BT, Tafa B, Alemu G, Wondimu F, et al. Maternal health care services utilization amidst COVID-19 pandemic in West Shoa zone, central Ethiopia. PLoS ONE. 2021;16:e0249214.

23. Temesgen K, Workie A, Dilnessa T, Getaneh E. The impact of COVID-19 infection on maternal and reproductive health care services in Governmental Health Institutions of Dessie Town, North-East Ethiopia. J Women's Health Care. 2020;10:518. https://doi.org/10.35248/2167-0420.21.10.518.

24. Belay L, Hurisa T, Abbas F, Daba M, Abebe B, Nigatu B, et al. Effect of COVID-19 pandemic on safe abortion and contraceptive services and mitigation measures: a case study from a tertiary facility in Ethiopia. EJRH. 2020;12:51-7.

25. Addis Ababa Population in 2021. Accessed 20 Sept 2021: https://world populationreview.com/world-cities/addis-ababa-population.

26. The Last Ten Kilometers Project (L1OK). Responsiveness to COVID-19 pandemic and its Immediate Impacts on Essential RMNCH Services in Addis Ababa. Accessed 30 Aug 2021: https://I10k.jsi.com/Resources/Docs/respo nsiveness-COVID-19-impacts-essential-RMNCH.pdf.

27. Kassie A, Wale A, Yismaw W. Impact of coronavirus diseases-2019 (COVID-19) on utilization and outcome of reproductive, maternal, and Newborn Health Services at Governmental Health Facilities in South West Ethiopia, 2020: comparative cross-sectional study. Int J Womens Health. 2021:13:479-88. 
28. Mekonnen T, Dune T, Perz J, Ogbo FA. Postnatal Care Service Utilization in Ethiopia: Reflecting on 20 Years of Demographic and Health Survey Data. Int J Environ Res Public Health. 2021;18:193.

29. Plan International. COVID-19: lockdown linked to high number of unintended teen pregnancy in Kenya. 2020. Accessed 1 Oct 2021: https:// plan-international.org/news/2020-06-25-covid-19-lockdown-linked-highnumber-unintended-teen-pregnancies-kenya.

30. Asratie MH. Unintended pregnancy during COVID-19 pandemic among women attending antenatal care in Northwest Ethiopia: magnitude and associated factors. Int J Women's Health. 2021;13:461-6.

31. Federal democratic republic of Ethiopia ministry of health. Policy, planning and monitoring \& evaluation directorate. HMIS indicators reference guide. June 2018. Accessed 5 Oct 2021: http://www.aau.edu.et/chs/? wpdmact $=$ process\&did $=M z \mid 4 L m h v d G x p b m s$.

32. Ethiopian Public Health Institute. National Public Health Emergency Operation Center. COVID-19 Pandemic Preparedness and Response weekly bulletin. Bulletin No. 12, July 20, 2020. Addis Ababa, Ethiopia. Accessed 5 Oct 2021: https://ephi.gov.et/download/pheoc/.

33. Federal Ministry of Health of Ethiopia (FMoH). National ComprehensiveCOVID-19 Management Handbook. Addis Ababa: FMoH 2020. Accessed 5 Oct 2021: https://www.moh.gov.et/ejcc/sites/default/files/202004/ COVID\%2019\%20Handbook\%20for\%20health\%20professionals\% 20FMOH\%202020.pdf.

34. Vora KS, Saiyed S, Natesan S. Impact of COVID-19 on family planning services in India. Sex Reprod Health Matters. 2020;28:1785378.

35. McGinn T. Reproductive health of war-affected populations: what do we know? Int Fam Plan Perspect. 2000;26:174.

36. World Health Organization/Africa. Ethiopia vaccinates nearly 15 million children against measles despite COVID-19 challenges. Accessed 5 Oct 2021: https://www.afro.who.int/news/ethiopia-vaccinates-nearly-15-milli on-children-against-measles-despite-covid-19-challenges.

37. World Health Organization. Routine immunization services during the COVID-19 pandemic. WHO 2020. Accessed 5 Oct 2021: https://apps.who. int/iris/bitstream/handle/10665/331925/Routine-immunization-servicesCOVID-19-eng.pdf.

38. Abbas K, Procter SR, Zandvoort KV, Clark A, Funk S, Mengistu T, et al. Routine childhood immunization during the COVID-19 pandemic in Africa: a benefit-risk analysis of health benefits versus excess risk of SARS-CoV-2 infection. Lancet Glob Health. 2020;8:e1264-72.

39. Keleb A, Sisay T, Alemu K, Ademas A, Lingerew M, Kloos H, et al. Pneumonia remains a leading public health problem among underfive children in peri-urban areas of northeastern Ethiopia. PLOS ONE. 2020;15:e0235818.

40. Hirvonen K, Berhane G, Assefa TW. Assessing community health information systems: evidence from child health records in food insecure areas of the Ethiopian Highlands. Matern Child Health J. 2020;24:1028-37.

41. Lee S, Kim E, Desta TB. Gaps in team communication about service statistics among health extension workers in Ethiopia: secondary data analysis. JMIR Mhealth Uhealth. 2020:8:e20848.

\section{Publisher's Note}

Springer Nature remains neutral with regard to jurisdictional claims in published maps and institutional affiliations.

Ready to submit your research? Choose BMC and benefit from:

- fast, convenient online submission

- thorough peer review by experienced researchers in your field

- rapid publication on acceptance

- support for research data, including large and complex data types

- gold Open Access which fosters wider collaboration and increased citations

- maximum visibility for your research: over $100 \mathrm{M}$ website views per year

At BMC, research is always in progress.

Learn more biomedcentral.com/submissions 